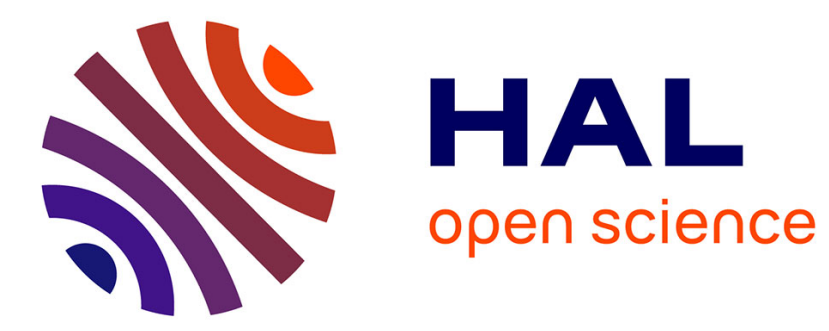

\title{
Fibers orientation optimization for concrete beam strengthened with a CFRP bonded plate: A coupled analytical-numerical investigation
}

\author{
Baghdad Krour, Fabrice Bernard, Abdelouahed Tounsi
}

\section{To cite this version:}

Baghdad Krour, Fabrice Bernard, Abdelouahed Tounsi. Fibers orientation optimization for concrete beam strengthened with a CFRP bonded plate: A coupled analytical-numerical investigation. Engineering Structures, 2013, 56, pp.218-227. 10.1016/j.engstruct.2013.05.008 . hal-00839542

\section{HAL Id: hal-00839542 \\ https://hal.science/hal-00839542}

Submitted on 28 Jun 2013

HAL is a multi-disciplinary open access archive for the deposit and dissemination of scientific research documents, whether they are published or not. The documents may come from teaching and research institutions in France or abroad, or from public or private research centers.
L'archive ouverte pluridisciplinaire $\mathbf{H A L}$, est destinée au dépôt et à la diffusion de documents scientifiques de niveau recherche, publiés ou non, émanant des établissements d'enseignement et de recherche français ou étrangers, des laboratoires publics ou privés. 


\title{
FIBERS ORIENTATION OPTIMIZATION FOR CONCRETE BEAM STRENGTHENED WITH A CFRP BONDED PLATE: A COUPLED ANALYTICAL-NUMERICAL INVESTIGATION
}

\author{
Baghdad Krour $^{\text {a,b,* }}$, Fabrice Bernard ${ }^{\text {b }}$, Abdelouahed Tounsi ${ }^{\text {a }}$ \\ ${ }^{a}$ Laboratoire des Matériaux et Hydrologie, Université de Sidi Bel Abbes, Algérie \\ ${ }^{b}$ UEB-INSA Rennes, Laboratoire de Génie Civil et Génie mécanique (LGCGM), France \\ * Corresponding author \\ kr_bag@yahoo.fr \\ Tel : +213(0)552077883 / +213(0) 48552099
}




\begin{abstract}
Important failure mode of such plated beams is the debonding of the FRP plates from the concrete due to high level of stress concentration in the adhesive at the ends of the FRP plate. This paper presents a new method for reducing interfacial stresses in a concrete beam bonded with the FRP plate by including the effect of the fiber orientation in the FRP plate. This work is divided into two parts; the first one is based on the laminates theory for the analytical solution where a minimization method is used to directly determine the fiber orientation reducing the interfacial stresses. The second part consists into a Finite Element modeling where the analytical solution and different fibers orientation combinations are tested for improving strengthening quality. Numerical results from the present analysis are presented in order to show the advantages of the present solution over existing ones and to reconcile debonding stresses with strengthening quality.
\end{abstract}

\title{
Keywords
}

Concrete beam, FRP composites; Interfacial stresses; Fibers orientations; Strengthening 


\section{Introduction}

Strengthening reinforced concrete beams by plating FRP laminates represents a new technology in the civil engineering field. This technique has many advantages including ease of application due to the high strength-to-weight ratio of FRP, conserving aesthetic aspect of the structure, and high corrosion resistance.

One of the main disadvantages of this technique is the debonding of the FRP plates from the concrete, particularly at the ends of the FRP plate. Consequently, many studies have been carried out in order to understand the failure mechanism of plated or connected beams [1-14] or laminated glass [15]. These studies converge to an important aspect: the presence of shear and normal stresses at the plate-core interface. In fact, these stresses can produce the brittle fracture of the concrete layer, which supports the composite laminate, followed by the premature failure of the strengthened beam. Many closedform solutions have been developed by researchers for the interfacial stresses [16-35]. Smith and Teng's solution [21] gives an accurate estimation of interfacial stresses but does not take into account the FRP plate fiber orientation. Other solutions have been presented in order to improve the solution developed by Smith and Teng [21]. In fact Tounsi et al. [22] have proposed a new approach taking into account the adherends shear deformations and neglecting fibers orientation effect too. Lau et al. [9] have presented a simple theoretical model to estimate the interfacial stresses taking into account the FRP plate fibers orientation. However, this method ignores the plate bending deformations effects and the flexural rigidity of the composite plate is not well estimated to compute the interfacial normal stresses.

Tounsi and Benyoucef [23] have presented a new method in which the FRP plate fiber orientation is considered and the flexural rigidity of the composite plate is not neglected. A sensitivity analysis has been presented considering different fibers orientation combinations.

In this paper, the same approach as Tounsi and Benyoucef [23] for interfacial stresses expressions is considered. However a new method enabling to obtain the minimum of interfacial stresses by minimizing process is presented. This process gives directly the fibers orientation combination presenting the minimum of debonding risk conversely to Tounsi and Benyoucef [23] where a parameter study varying fiber orientation combinations is used. A Finite Element investigation is also presented in this paper to verify the analytical method and to test the strengthening quality of the optimum solution for debonding stresses.

\section{System definition and assumptions:}

The derivation of the solution below is described in terms of adherends 1 and 2 (Fig. 1 and 2), where adherend 1 is the concrete beam and adherend 2 is the soffit plate. Adherend 2 can be either steel or FRP but not limited to these ones. 
The following assumptions are made :

1. The concrete, adhesive, and FRP materials behave elastically and linearly.

2. No slip is allowed at the interface of the bond (i.e. there is a perfect bond at the adhesive-concrete interface and at the adhesive-plate interface).

3. Stresses in the adhesive layer do not change with the thickness.

4. Deformations of adherends 1 and 2 are due to bending moments and axial forces.

5. The shear stress analysis assumes that the curvatures in the beam and plate are equal (since this allows the shear stress and peel stress equations to be uncoupled). However, this assumption is not made in the peel stress solution. This assumption is used in several works e.g. Smith and Teng [21],

A. Tounsi [22].

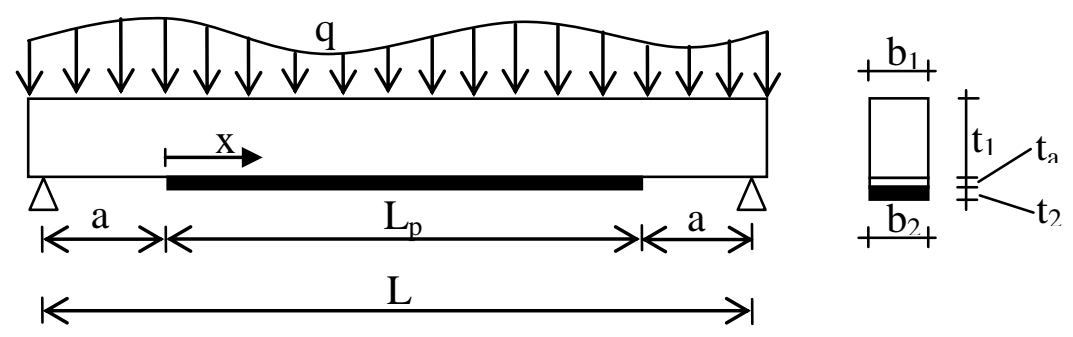

Fig. 1. Simply supported beam strengthened with bonded FRP plate
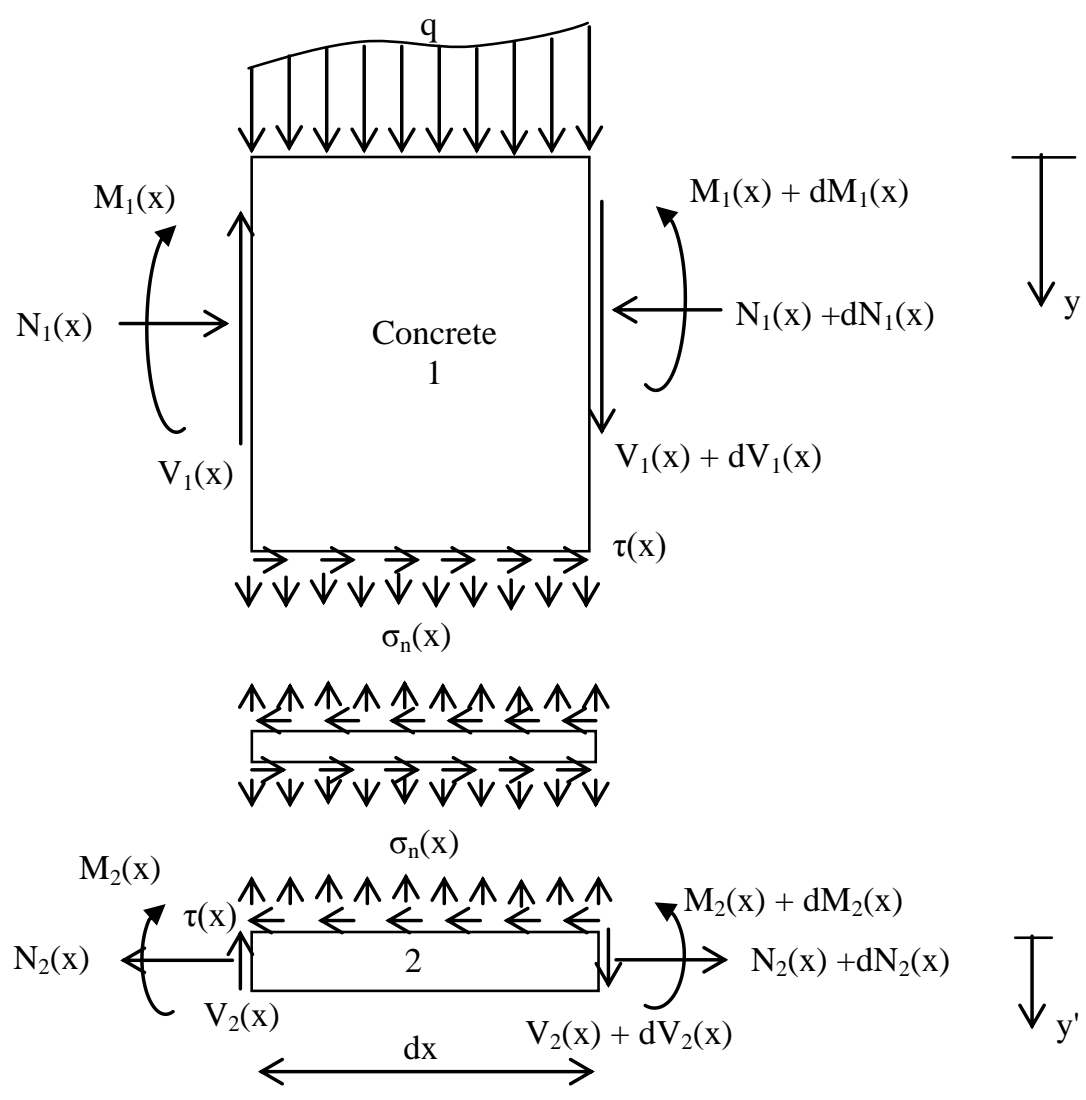

Fig. 2. Forces in the infinitesimal element of a soffit-plated beam. 


\section{Analytical equations:}

\subsection{Adhesive shear stress: governing differential equation:}

In this part, q is assumed to be uniformly distributed load.

A differential segment, $d x$ of the plated beam is shown in fig. 2 where all the forces and stresses are represented with their signs. We denote $\tau(x)$ and $\sigma(x)$, respectively as the interfacial shear and the normal stresses.

The shear strain in the adhesive layer is expressed as:

$$
\gamma_{x y}=\frac{\partial u(x, y)}{\partial y}+\frac{\partial w(x, y)}{\partial x} \approx \frac{u_{2}(x)-u_{1}(x)}{t_{a}}
$$

Consequently, the shear stress in the adhesive layer is given by:

$$
\tau(x)=G_{a}\left[\frac{u_{2}(x)-u_{1}(x)}{t_{a}}\right]
$$

Where $G_{a}, t_{a}, u_{1}$ and $u_{2}$ denote respectively the shear modulus, the thickness of the adhesive layer, the horizontal displacement at the bottom of the concrete beam, and the horizontal displacement at the top of the externally bonded FRP plate. Differentiating Eq. (2) with respect to $x$ gives the shear stress expression in terms of the mechanical strain of the concrete $\varepsilon_{1}(x)$ and the FRP plate $\varepsilon_{2}(x)$ :

$$
\frac{d \tau(x)}{d x}=G_{a}\left[\frac{\varepsilon_{2}(x)-\varepsilon_{1}(x)}{t_{a}}\right]
$$

The strain at the bottom of adherend 1 is given by:

$$
\varepsilon_{1}(x)=\frac{d u_{1}(x)}{d x}=\frac{y_{1}}{E_{1} I_{1}} M_{1}(x)-\frac{1}{E_{1} A_{1}} N_{1}(x)
$$

Where $E_{1}$ is the elastic modulus, $A_{1}$ the cross-sectional area, $M_{1}$ the bending moment, $N_{1}$ the axial force and $y_{1}$ the distance from the bottom of adherend 1 to its center.

In this study, the laminate theory [36] is used to highlight the fibers orientation effect on the behavior of the externally bonded composite plate. Using this theory for a symmetrical composite plate [36], the mid-plane strain $\varepsilon_{x}^{0}$ and the Curvature $k_{x}$ of the composite plate are given as:

$$
\varepsilon_{x}^{0}=A_{11}^{\prime} N_{x} \frac{1}{b_{2}} \text { and } k_{x}=D_{11}^{\prime} M_{x} \frac{1}{b_{2}}
$$




\section{Where:}

$\left[A^{\prime}\right]=[A]^{-1}$ is the inverse of the extensional matrix $[A] ;\left[D^{\prime}\right]=[D]^{-1}$ is the inverse of the flexural matrix $[D]$; and $b_{2}$ is the width of FRP plate.

Explicitly, the terms of the matrices $[A]$ and $[D]$ are written as:

$$
A_{m n}=\sum_{j=1}^{N} \bar{Q}_{m n}\left(h_{j}-h_{j-1}\right) \text { and } D_{m n}=\sum_{j=1}^{N} \bar{Q}_{m n}\left(h_{j}^{3}-h_{j-1}^{3}\right)
$$

Where:

$$
\left\{\begin{array}{l}
\bar{Q}_{11}=\left[\frac{E_{11}}{1-v_{12} v_{21}}\right] \cos ^{4}\left(\theta_{j}\right)+\left[\frac{E_{22}}{1-v_{12} v_{21}}\right] \sin ^{4}\left(\theta_{j}\right)+2\left[\frac{v_{12} E_{22}}{1-v_{12} v_{21}}+2 G_{12}\right] \cos ^{2}\left(\theta_{j}\right) \sin ^{2}\left(\theta_{j}\right) \\
\bar{Q}_{22}=\left[\frac{E_{11}}{1-v_{12} v_{21}}\right] \sin ^{4}\left(\theta_{j}\right)+\left[\frac{E_{22}}{1-v_{12} v_{21}}\right] \cos ^{4}\left(\theta_{j}\right)+2\left[\frac{v_{12} E_{22}}{1-v_{12} v_{21}}+2 G_{12}\right] \cos ^{2}\left(\theta_{j}\right) \sin ^{2}\left(\theta_{j}\right)(7) \\
\bar{Q}_{12}=\frac{v_{12} E_{22}}{1-v_{12} v_{21}}\left[\cos ^{4}\left(\theta_{j}\right)+\sin ^{4}\left(\theta_{j}\right)\right]+\left[\frac{E_{11}}{1-v_{12} v_{21}}+\frac{E_{22}}{1-v_{12} v_{21}}-4 G_{12}\right] \cos ^{2}\left(\theta_{j}\right) \sin ^{2}\left(\theta_{j}\right) \\
\bar{Q}_{33}=G_{12}
\end{array}\right.
$$

Where $j$ is number of the layer; $h ;[\bar{Q}]$ and $\theta_{j}$ are respectively the thickness, the Hooke's elastic tensor and the fibers orientation of each layer.

Using classical laminate theory, the strain at the top of adherend 2 is given by:

$$
\varepsilon_{2}(x)=\frac{d u_{2}(x)}{d x}=\varepsilon_{x}^{0}-\frac{t_{2}}{2} \cdot k_{x}
$$

Substituting Eq. (5) in (8) gives the following equation:

$$
\varepsilon_{2}(x)=A_{11}^{\prime} \frac{N_{2}(x)}{b_{2}}-D_{11}^{\prime} \frac{t_{2}}{2 b_{2}} M_{2}(x)
$$

Where $N_{2}(x)=N_{x}$ and $M_{2}(x)=M_{x}$.

The subscripts 1 and 2 denote respectively adherends 1 and 2. $M(x), N(x)$ are the bending and axial force in each adherend.

The horizontal forces equilibrium gives:

$$
\frac{d N_{1}(x)}{d x}=\frac{d N_{2}(x)}{d x}=b_{2} \tau(x)
$$


And then:

$$
N_{1}(x)=N_{2}(x)=b_{2} \int_{0}^{x} \tau(x) d x
$$

Assuming equal curvature in the beam and the FRP plate (perfect contact) it is obtained:

$$
\frac{d^{2} w_{2}(x)}{d x^{2}}=\frac{d^{2} w_{1}(x)}{d x^{2}}
$$

The relationship between the moments in the two adherends can be written as follows:

$$
M_{1}(x)=R M_{2}(x)
$$

With: $\quad R=-\frac{E_{1} I_{1} D_{11}^{\prime}}{b_{2}}$

The moment equilibrium gives:

$$
M_{T}(x)=M_{1}(x)+M_{2}(x)+N(x)\left[y_{1}+\frac{t_{2}}{2}+t_{a}\right]
$$

where, $M_{T}(x)$ is the total applied moment.

The bending moments in each adherend are so expressed as a function of the total applied moment and the interfacial shear stress as follows:

$$
M_{1}(x)=\frac{R}{R+1}\left[M_{T}(x)-b_{2} \int_{0}^{x} \tau(x)\left(y_{1}+\frac{t_{2}}{2}+t_{a}\right) d x\right]
$$

and

$$
M_{2}(x)=\frac{1}{R+1}\left[M_{T}(x)-b_{2} \int_{0}^{x} \tau(x)\left(y_{1}+\frac{t_{2}}{2}+t_{a}\right) d x\right]
$$

The first derivative of the bending moment in each adherend gives:

$$
\begin{aligned}
& \frac{d M_{1}(x)}{d x}=\frac{R}{R+1}\left[V_{T}(x)-b_{2} \tau(x)\left(y_{1}+\frac{t_{2}}{2}+t_{a}\right)\right] \\
& \frac{d M_{2}(x)}{d x}=\frac{1}{R+1}\left[V_{T}(x)-b_{2} \tau(x)\left(y_{1}+\frac{t_{2}}{2}+t_{a}\right)\right]
\end{aligned}
$$


Substituting Eqs. (3) and (9) into Eq. (3) and differentiating the resulting equation once yields:

$$
\frac{d^{2} \tau(x)}{d x^{2}}=\frac{G_{a}}{t_{a}}\left(\frac{A_{11}^{\prime}}{b_{2}} \frac{d N_{2}(x)}{d x}-D_{11}^{\prime} \frac{t_{2}}{2 b_{2}} \frac{d M_{2}(x)}{d x}+\frac{1}{E_{1} A_{1}} \frac{d N_{1}(x)}{d x}-\frac{y_{1}}{E_{1} I_{1}} \frac{d M_{1}(x)}{d x}\right)
$$

Substituting Eqs. (18), (19) and Eq. (10) into Eq. (20) gives the following governing differential equation for the interfacial shear stress:

$$
\frac{d^{2} \tau(x)}{d x^{2}}-\frac{G_{a}}{t_{a}}\left(A_{11}^{\prime}+\frac{b_{2}}{E_{1} A_{1}}+\frac{\left(y_{1}+\frac{t_{2}}{2}\right)\left(y_{1}+\frac{t_{2}}{2}+t_{a}\right)}{E_{1} I_{1} D_{11}^{\prime}+b_{2}} b_{2} D_{11}^{\prime}\right) \tau(x)+\frac{G_{a}}{t_{a}}\left(\frac{\left(y_{1}+\frac{t_{2}}{2}\right)}{E_{1} I_{1} D_{11}^{\prime}+b_{2}} D_{11}^{\prime}\right) V_{T}(x)=0
$$

The general solutions presented below are limited to loading which is either concentrated or uniformly distributed, or both. For such loading $d^{2} V_{T}(x) / d x^{2}=0$, and the general solution to Eq. (21) is given by:

$$
\tau(x)=B_{1} \cosh (\lambda x)+B_{2} \sinh (\lambda x)+m_{1} V_{T}(x)
$$

Where:

$$
\begin{aligned}
& \lambda^{2}=\frac{G_{a}}{t_{a}}\left(A_{11}^{\prime}+\frac{b_{2}}{E_{1} A_{1}}+\frac{\left(y_{1}+\frac{t_{2}}{2}\right)\left(y_{1}+\frac{t_{2}}{2}+t_{a}\right)}{E_{1} I_{1} D_{11}^{\prime}+b_{2}} b_{2} D_{11}^{\prime}\right) \\
& m_{1}=\frac{G_{a}}{t_{a}}\left(\frac{\left(y_{1}+\frac{t_{2}}{2}\right)}{E_{1} I_{1} D_{11}^{\prime}+b_{2}} D_{11}^{\prime}\right)
\end{aligned}
$$

$B_{1}$ and $B_{2}$ are constant coefficients determined from the boundary conditions.

\subsection{Adhesive Normal stress: governing differential equations:}

The strain in the adhesive layer is given by:

$$
\varepsilon_{y}=\frac{\partial w(x, y)}{\partial y} \approx \frac{w_{2}(x)-w_{1}(x)}{t_{a}}
$$

Where $w_{1}(x)$ and $w_{2}(x)$ are the vertical displacements of adherends 1 and 2 respectively. 
The normal stress in the adhesive layer is expressed as follows:

$$
\sigma(x)=\frac{E_{a}}{t_{a}}\left[w_{2}(x)-w_{1}(x)\right]
$$

Differentiating Eq. (26) two times gives:

$$
\frac{d^{2} \sigma(x)}{d x^{2}}=\frac{E_{a}}{t_{a}}\left[\frac{d^{2} w_{2}(x)}{d x^{2}}-\frac{d^{2} w_{1}(x)}{d x^{2}}\right]
$$

The moment-curvature relationship for the two adherends is expressed as follows:

$$
\frac{d^{2} w_{1}(x)}{d x^{2}}=-\frac{M_{1}(x)}{E_{1} I_{1}}, \quad \frac{d^{2} w_{2}(x)}{d x^{2}}=-\frac{D_{11}^{\prime} M_{2}(x)}{b_{2}}
$$

The moment equilibrium of adherends 1 and 2 gives:

Adherend 1: $\quad \frac{d M_{1}(x)}{d x}=V_{1}(x)-b_{2} y_{1} \tau(x)$ and $\frac{d V_{1}(x)}{d x}=-b_{2} \sigma(x)-q$

Adherend 2: $\quad \frac{d M_{2}(x)}{d x}=V_{2}(x)-b_{2} \frac{t_{2}}{2} \tau(x) \quad$ et $\frac{d V_{2}(x)}{d x}=b_{2} \sigma(x)$

Where $q$ is the uniformly distributed load.

Using the above equilibrium equations, the governing differential equations for the deflection of each adherend are given by:

Adherend 1: $\quad \frac{d^{4} w_{1}(x)}{d x^{4}}=\frac{1}{E_{1} I_{1}} b_{2} \sigma(x)+\frac{y_{1}}{E_{1} I_{1}} b_{2} \frac{d \tau(x)}{d x}+\frac{q}{E_{1} I_{1}}$

Adherend 2: $\quad \frac{d^{4} w_{2}(x)}{d x^{4}}=-D_{11}^{\prime} \sigma(x)+D_{11}^{\prime} \frac{t_{2}}{2} \frac{d \tau(x)}{d x}$

Substituting both Eqs. (31), (19) and Eq. (32) into the fourth derivation of the interfacial normal stress obtained from Eq. (26) gives the following governing differential equation for the interfacial normal stress:

$$
\frac{d^{4} \sigma(x)}{d x^{4}}+\frac{E_{a}}{t_{a}}\left(D_{11}^{\prime}+\frac{b_{2}}{E_{1} I_{1}}\right) \sigma(x)-\frac{E_{a}}{t_{a}}\left(D_{11}^{\prime} \frac{t_{2}}{2}-\frac{y_{1} b_{2}}{E_{1} I_{1}}\right) \frac{d \tau(x)}{d x}+\frac{q E_{a}}{E_{1} I_{1}}=0
$$

The general solution of Eq. (33) which is a fourth-order differential equation is:

$$
\sigma(x)=e^{-\beta x}\left[C_{1} \cos (\beta x)+C_{2} \sin (\beta x)\right]+e^{\beta x}\left[C_{3} \cos (\beta x)+C_{4} \sin (\beta x)\right]-n_{1} \frac{d \tau(x)}{d x}-n_{2} q
$$


For large values of $x$ it is assumed that the normal interfacial stress tends to zero, and as a consequence, $C_{3}=C_{4}=0$.

The general equation becomes:

$$
\sigma(x)=e^{-\beta x}\left[C_{1} \cos (\beta x)+C_{2} \sin (\beta x)\right]-n_{1} \frac{d \tau(x)}{d x}-n_{2} q
$$

Where:

$$
\begin{aligned}
& \beta=\sqrt[4]{\frac{E_{a}}{4 t_{a}}\left(D_{11}^{\prime}+\frac{b 2}{E_{1} I_{1}}\right)} \\
& n_{1}=\frac{y_{1} b_{2}-E_{1} I_{1} D_{11}^{\prime}\left(\frac{t_{2}}{2}\right)}{E_{1} I_{1} D_{11}^{\prime}+b_{2}}
\end{aligned}
$$

and

$$
n_{2}=\frac{1}{E_{1} I_{1} D_{11}^{\prime}+b_{2}}
$$

$C_{1}$ and $C_{2}$ are constant coefficients determined from the boundary conditions.

\subsection{Application of the boundary conditions and closed-form solutions:}

After deriving the general solution for the interfacial shear and normal stresses, only the case of uniformly distributed load applied for a simply supported beam is considered in this study.

The following boundary conditions are thus considered:

$$
\left\{\begin{array}{l}
N_{1}(0)=N_{2}(0)=0 \\
M_{2}(0)=0 \\
\tau\left(L_{p} / 2\right)=0
\end{array}\right.
$$

These boundary conditions give the interfacial shear stress described by Smith and Teng [21] and written as:

$$
\tau(x)=\left[\frac{m_{2} a}{2}(L-a)-m_{1}\right] \frac{q e^{-\lambda x}}{\lambda}+m_{1} q\left(\frac{L}{2}-a-x\right) \quad \text { and } \quad 0 \leq x \leq L_{p}
$$

Where $q$ is the uniformly distributed load and $x, a, L$ and $L_{p}$ are defined in Fig. 2.

The parameter $m_{2}$ is given by:

$$
m_{2}=\frac{G_{a} y_{1}}{t_{a} E_{1} I_{1}}
$$


The constant coefficients $C_{1}$ and $C_{2}$ for the normal interfacial stress are given by:

$$
\begin{aligned}
& C_{1}=\frac{E_{a}}{2 \beta^{3} t_{a} E_{1} I_{1}}\left[V_{T}(0)+\beta M_{T}(0)\right]-\frac{n_{3}}{2 \beta^{3}} \tau(0)+\frac{n_{1}}{2 \beta^{3}}\left(\frac{d^{4} \tau(0)}{d x^{4}}+\beta \frac{d^{3} \tau(0)}{d x^{3}}\right) \\
& C_{2}=\frac{E_{a}}{2 \beta^{2} t_{a} E_{1} I_{1}} M_{T}(0)-\frac{n_{1}}{2 \beta^{2}} \frac{d^{3} \tau(0)}{d x^{3}}
\end{aligned}
$$

Where:

$$
n_{3}=\frac{E_{a} b_{2}}{t_{a}}\left(\frac{y_{1}}{E_{1} A_{1}}-\frac{D_{11}^{\prime} t_{2}}{2 b_{2}}\right)
$$

\subsection{Minimization process:}

It is obvious that the expressions of shear and normal interfacial stresses depend on $x$ and $\theta_{\mathrm{j}}$

$$
\left\{\begin{array}{l}
\tau \rightarrow f\left(x, \theta_{j}\right) \\
\sigma \rightarrow f\left(x, \theta_{j}\right)
\end{array}\right.
$$

Independently of the values of $\theta_{j}$, the above functions reach their maximum at $x=0$.

Fixing $x$ at zero, it is possible to search the values of $\theta_{j}$ which give the minimum of the shear and normal interfacial stresses.

As the aim of the work is to reduce the risk of the FRP plates debonding from the concrete beam, it is proposed in the following to find the $\theta_{\mathrm{j}}$-values minimizing the shear and normal interfacial stresses.

In this work, Matlab program is used to find the minimum of shear and normal stresses. The minimization process in Matlab is based on the Nelder-Mead method proposed by John Nelder \& Roger Mead [37] which is a technique for minimizing an objective function in a many-dimensional space. The method approximates a local optimum of a problem with $N$ variables when the objective function varies smoothly and is unimodal.

The Nelder-Mead algorithm is based on the iterative update of a simplex made of $n+1$ points. Each point in the simplex is called a vertex and is associated with a function value. The vertices are sorted by increasing function values so that the best vertex has index 1 and the worst vertex has index $n+1$. In each iteration, we compute a centroid without taking into account the worst vertex

The centroid is given as: $\bar{x}(j)=\frac{1}{n} \sum_{i=1, n+1, i \neq j} v_{i}$

A new vertex is defined in order to replace the worst vertex. The new point is calculated as follow:

$$
x(\rho, j)=(1+\rho) \bar{x}(j)-\rho v_{j}
$$


Where $\rho$ is a positive coefficient taken by default equal to 1 . Then the function values are sorted once again and the process is repeated until the minimum is found.

Matlab allows the use of the Nelder-Mead method by introducing the FMINUNC command in the program. The syntax of this command is "X = FMINUNC (FUN, X0)", where $\mathrm{X}$ is the result vector containing the values minimizing the objective function, FUN is the objective function and $\mathrm{X} 0$ is the initial values vector. The objective function must be defined in a separate file with the key word "function". The first derivative of the objective function must be also defined in the function file.

\subsection{Model prediction results and validation}

In order to check the present method, it is chosen to compare it with the closed-form solution presented by Tounsi et al. [23] in which a sensitivity analysis on the fiber orientation of the CFRP bonded plate has been performed. It has been particularly shown that the minimum of shear and normal stresses is reached when all the fibers of each layer are oriented perpendicularly to the longitudinal axis of the CFRP bonded plate.

Thus, a Concrete beam bonded with a CFRP soffit plate is considered. The beam is simply supported and subjected to a uniformly distributed load. The span of the Concrete beam is $L=3000 \mathrm{~mm}$, the distance from the support to the end of the plate is $a=300 \mathrm{~mm}$ and the UDL is $50 \mathrm{kN} / \mathrm{m}$. The CFRP bonded plate is made of 16 symmetrical layers. Table 1 shows the geometrical and material properties of the studied beam. In table 2 it can be seen that all the orientation angles $\theta_{\mathrm{j}}$ giving the minimum of the shear and normal stresses are near to the value of $\pi / 2$. This result is in perfect agreement with the main conclusions presented by Tounsi et al. [23]

Moreover, Fig $3 \mathrm{a}$ and $\mathrm{b}$ show the interfacial shear and normal stresses distributions in the concrete beam bonded with a CFRP plate using the optimum fibers orientation compared with the evaluated interfacial shear and normal stresses obtained by Tounsi et al. [23]. It can be seen that the optimum fibers orientation agree perfectly with a composite plate in which all the fibers are oriented with an angle equal to $90^{\circ}$.

Table 1: Geometrical and material proprieties

\begin{tabular}{|c|c|c|c|c|c|c|}
\hline Materials & Width $(\mathrm{mm})$ & Depth $(\mathrm{mm})$ & $E_{11}(\mathrm{GPa})$ & $E_{22}(\mathrm{GPa})$ & $G_{12}(\mathrm{GPa})$ & $v$ \\
\hline Concrete beam & $b_{1}=200$ & $t_{1}=300$ & 30 & 30 & & 0.18 \\
\hline $\begin{array}{c}\text { Adhesive layer } \\
b_{\mathrm{a}}=200\end{array}$ & $t_{\mathrm{a}}=4$ & 3 & 3 & & 0.35 \\
\hline $\begin{array}{c}\text { CFRP plate* } \\
16 \text { layers }\end{array}$ & $b_{2}=200$ & $t_{2}=4$ & 140 & 10 & 5 & \\
\hline
\end{tabular}


Table 2: minimization results

\begin{tabular}{|c|c|c|c|c|c|c|c|c|c|}
\hline \multirow{2}{*}{$\begin{array}{c}\text { Interfacial } \\
\text { stresses }\end{array}$} & \multicolumn{8}{|c|}{ Fiber Orientation angles } \\
\cline { 2 - 10 } & $\theta_{1}$ & $\theta_{2}$ & $\theta_{3}$ & $\theta_{4}$ & $\theta_{5}$ & $\theta_{6}$ & $\theta_{7}$ & $\theta_{8}$ & {$\left[(90)_{16}\right]_{\mathrm{s}}$} \\
\hline$\theta \mathrm{rad}$ & 1.5707 & 1.5707 & 1.5708 & 1.5708 & 1.5708 & 1.5708 & 1.5708 & 1.5708 & $\pi / 2$ \\
\hline$\tau_{\max }(\mathrm{MPa})$ & \multicolumn{8}{|c|}{0.7694} & 0.7694 \\
\hline$\theta$ & 1.6669 & 1.5732 & 1.5731 & 1.5729 & 1.5729 & 1.5726 & 1.5724 & 1.5723 & $\pi / 2$ \\
\hline$\sigma_{\max }(\mathrm{MPa})$ & \multicolumn{10}{|c|}{0.6389} & & 0.6384 \\
\hline
\end{tabular}
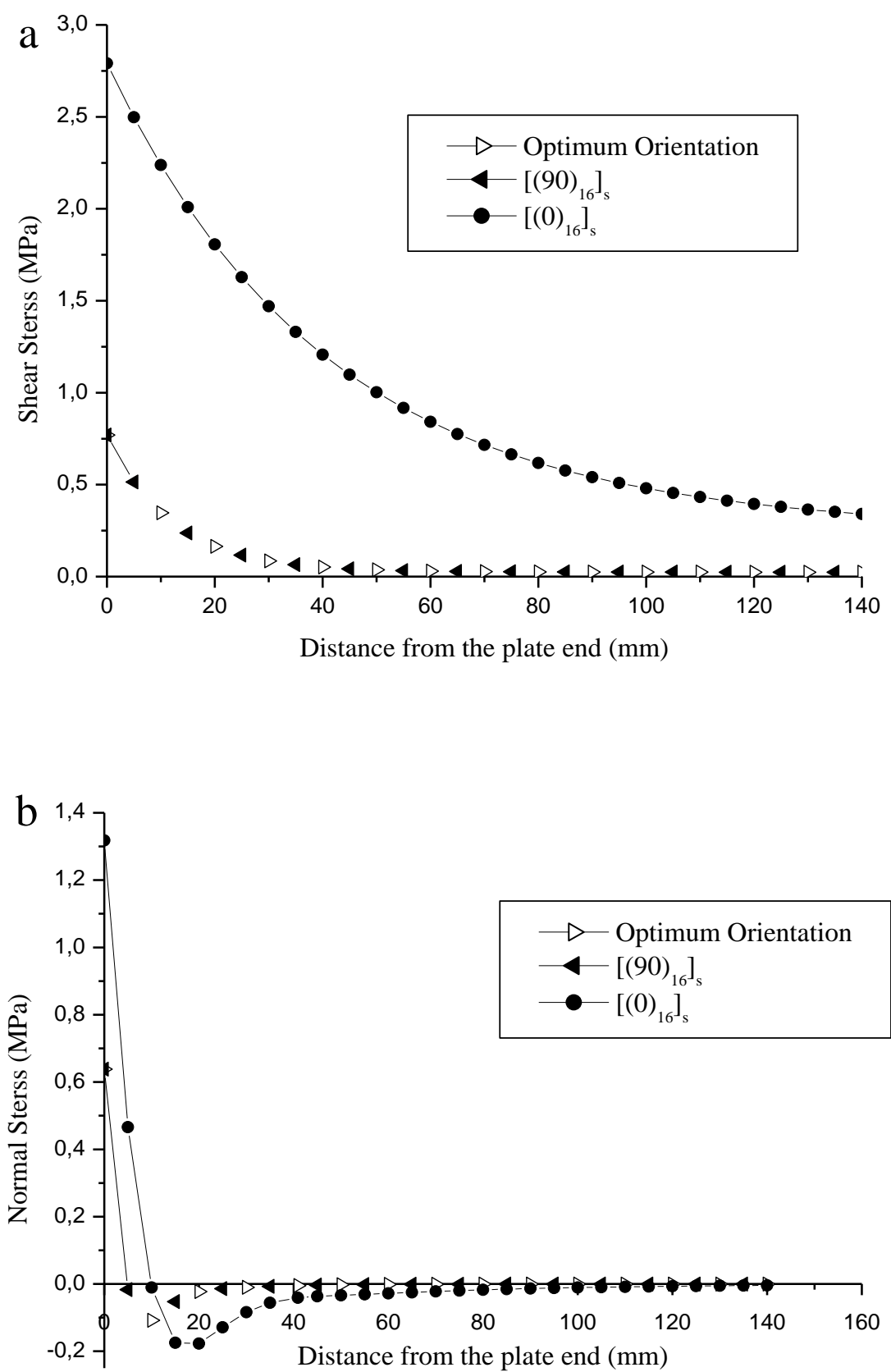

Fig. 3 . Comparison of interfacial shear and normal stresses in a CFRP-strengthened Concrete beam under a uniformly distributed load 


\section{Finite element Approach: determination of the most efficient fibers orientation}

A Finite Element model conducted with the general-purpose package Abaqus [38] is developed in this section. Such a modeling presents several advantages compared to previous analytical solutions. First it enables to investigate the inelastic mechanical behavior of the studied plated beam. This is the only way to assess accurately the load bearing capacity of the beam and to determine the efficiency of the reinforcement.

Then, the FE approach enables to complete valuably analytical developments. The advantage of simple approximate solutions is that they lead to relatively simple closed-form expressions for interfacial stresses. However this simplicity means that the predicted shear stress reaches its maximum value at the end of the adhesive layer, which violates the condition of stress-free end of the adhesive layer. Furthermore, a complex variation of the interfacial stresses through the adhesive layer cannot be captured by an analytical way. All these disadvantages can be avoided by a rigorous FE analysis.

In the following, this numerical analysis is divided into two parts: first the elastic computation will lead to a new determination of the interfacial stresses through the adhesive layer. Taking into account the fibers orientations, this computation will enable to check the previous closed-form solutions. Then, the inelastic computations using Lubliner's model as the constitutive model for concrete will be performed in order to determine the load bearing capacity of the plated beam and to investigate the quality of the strengthening.

\subsection{Elastic computation: validation and determination of the interfacial stresses}

\subsubsection{Assumptions of the modeling}

Initially a simply supported beam bonded with a soffit composite plate and subjected to a uniformly distributed load, as in the previous sections, is considered. The span of the beam is $3000 \mathrm{~mm}$, the length of the plate is $2400 \mathrm{~mm}$ and the UDL is $50 \mathrm{kN} / \mathrm{m}$. The geometric and material properties of the beam, the adhesive layer and the plate are those given in table 1 .

Four-node linear quadrilateral plane stress elements (CPS4) are used to model the plated beam and the Finite Element Mesh is shown in figure 4. Only half of the beam is modeled due the symmetry and a particularly finemesh is employed to model the adhesive layer at the plate near the plate end to obtain accurate results. 


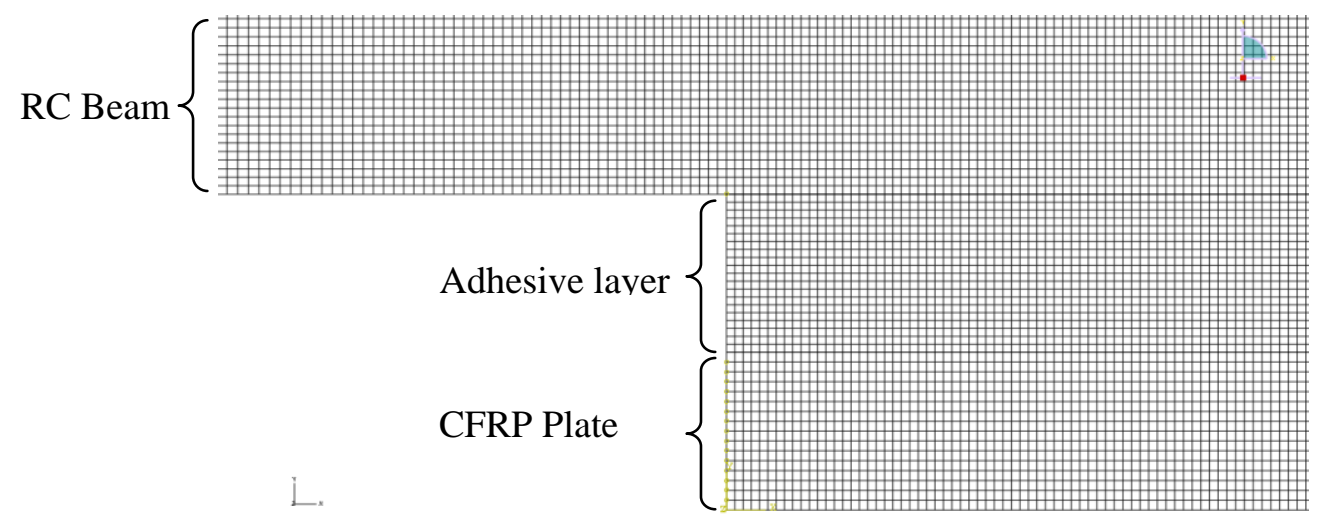

Fig.4. Mesh detail at the plate end.

The existence of points of singularity at the interfaces of the plate end presents a challenge to the choice of a suitable finite element mesh as the stresses at these points increase with the mesh refinement. A convergence study to determine the optimal mesh has been performed. Such an analysis is similar to the study of Zhang and Teng [27] where the same FE software was used.The variations of interfacial normal and shear stresses at the interfaces between adhesive and concrete beam and between adhesive and composite plate, but also at the mid-adhesive section are determined as the height of the smallest element has been reduced from 0.8 to $0.1 \mathrm{~mm}$. Based on this convergence study, a minimum element size of $0.2 \mathrm{~mm}$ has been selected as the use of even smaller elements lead to very small localized differences. This result has also been pointed out in [27].

In the longitudinal direction of the beam, a graded mesh has been used starting with an aspect ratio of 1 for the minimum height elements. As shown in figure 4, about the same pattern has been adopted for the soffit plate. In opposition to the former work of Zhang and Teng [27], the present model takes into account the fibers orientations in each layer of the composite plate. Thus the thickness of the plate is divided into 16 equal parts leading to an aspect ratio of the finite elements at the edge near to 1 . In each layer, a specific local orientation has been adopted accordingly to the fibers orientations and an orthotropic material has thus been defined (see table 1).

For the concrete beam, a graded mesh of matching fineness has been used. Using these mesh considerations, the model contains 705600 elements and 709000 nodes. Table 3 presents the repartition of nodes and elements number in the various constituents of the beam.

Table 3: elements and nodes numbers

\begin{tabular}{|l|l|l|l|}
\hline & Element type & Elements number & Nodes number \\
\hline Concrete beam & CPS4R & 675000 & 676851 \\
\hline Adhesive layer & CPS4R & 17000 & 17871 \\
\hline CFRP Plate & CPS4R & 13600 & 14467 \\
\hline Total & CPS4R & 705600 & 709189 \\
\hline
\end{tabular}


It is worth noting that, in this study, a steel rebar is not considered as it is the case in the previous analytical developments.

Furthermore, at the end of the concrete beam, the two components of the displacements in the plane have been blocked. This boundary condition has been imposed not only to the node located at the edge of the bottom of the beam, but also to its two neighbors. Indeed a displacement condition imposed to a single node may lead to severe computational difficulties. This numerical adjustment has no impact on the interfacial stresses in the adhesive layer since this last one is sufficiently far away the boundary condition.

\subsubsection{Results for various fibers orientations: computed interfacial stresses and comparisons with closed-form solutions}

Table 4 presents now the results of the modeling for various fiber orientations in terms of maximum shear and normal interfacial stresses. Contrary to the previous analytical approach, the FE model gives results at beam-adhesive (B-A), plate-adhesive (P-A) interfaces and at the middle of the adhesive (MA).

The minimum values of shear and normal interfacial stresses are obtained with a composite plate $\left[(90)_{16}\right]_{\mathrm{s}}$ in which all the fibers are oriented with an angle equal to $90^{\circ}$. This result is in agreement with the minimization process described in the above section. A composite plate $\left[(0)_{8}\right] \mathrm{s}$ of $2 \mathrm{~mm}$ thickness is also studied in order to show the effectiveness of the optimum solution.

Table 5 shows the profit percentage between a composite $\left[(0)_{16}\right]_{s}$ and $\left[(90)_{16}\right]_{s}$ which gives the maximum and the minimum of the shear and normal interfacial stresses. It is clear that the composite $\left[(90)_{16}\right]_{s}$ reduces considerably the debonding stresses.

Table 4: Results of the sensitivity analysis on fibers orientation

\begin{tabular}{|c|c|c|c|c|c|c|}
\hline \multirow{3}{*}{ Fibers orientation } & \multicolumn{6}{|c|}{ UDL $(50 \mathrm{kN} / \mathrm{m})$} \\
\hline & \multicolumn{3}{|c|}{$\tau_{\max }(\mathrm{MPa})$} & \multicolumn{3}{|c|}{$\sigma_{\max }(\mathrm{MPa})$} \\
\hline & A-B & M-A & $\mathrm{P}-\mathrm{A}$ & A-B & M-A & P-A \\
\hline$\left[(0)_{16}\right]_{\mathrm{s}}$ & 2.427 & 2.038 & 1.99 & 9.313 & 1.64 & -2.295 \\
\hline$\left[(0)_{8}\right]_{\mathrm{s}}(2 \mathrm{~mm}$ of thickness $)$ & 1.813 & 1.431 & 1.421 & 6.806 & 1.203 & -1.49 \\
\hline$\left[(90)_{8} /(45)_{8}\right]_{\mathrm{s}}$ & 0.927 & 0.532 & 0.468 & 3.072 & 0.534 & -0.35 \\
\hline$\left[(45)_{8} /(-45)_{8}\right]_{\mathrm{s}}$ & 0.969 & 0.579 & 0.51 & 3.42 & 0.555 & 0.43 \\
\hline$\left[(90)_{8} /(60)_{8}\right]_{\mathrm{s}}$ & 0.894 & 0.504 & 0.437 & 2.92 & 0.497 & -0.352 \\
\hline$\left[(90)_{8} /(0)_{8}\right]_{\mathrm{s}}$ & 1.888 & 1.469 & 1.423 & 7.08 & 1.287 & -1.52 \\
\hline$\left[(90)_{16}\right]_{\mathrm{s}}$ & 0.885 & 0.496 & 0.429 & 2.88 & 0.486 & -0.389 \\
\hline
\end{tabular}


Table 5: profit percentages

\begin{tabular}{|c|c|c|c|c|c|c|}
\hline \multirow{2}{*}{ Fibers orientation } & \multicolumn{5}{|c|}{ UDL $(50 \mathrm{kN} / \mathrm{m})$} \\
\cline { 2 - 7 } & \multicolumn{3}{|c|}{$\tau(\mathrm{MPa})$} & \multicolumn{3}{c|}{$\sigma(\mathrm{MPa})$} \\
\cline { 2 - 7 } & A-B & M-A & P-A & A-B & M-A & P-A \\
\hline$\left[(0)_{16}\right]_{\mathrm{s}}$ & 2.427 & 1.174 & 1.99 & 9.313 & 1.64 & -2.295 \\
\hline$\left[(90)_{16}\right]_{\mathrm{s}}$ & 0.885 & 0.496 & 0.429 & 2.88 & 0.486 & -0.389 \\
\hline Profit (\%) & 63.53 & 57.75 & 78.44 & 69.07 & 70.36 & 83.05 \\
\hline Mean value (\%) & \multicolumn{3}{|c|}{$66.57 \%$} & \multicolumn{4}{c|}{$74.16 \%$} \\
\hline
\end{tabular}

Fig. 5 (a) and (b) show the shear and normal interfacial stresses obtained with the optimum fibers orientation according to the distance from the plate end as well as the results of the Finite Element model using the same fibers orientation. It can be seen that numerical and analytical models are in agreement, except that the finite element model does not give the maximum interfacial stresses at the plate end, but at a short distance from it.

This last observation, without taking into account the fibers orientations in the composite plate, is in agreement with conclusions of Zhang and Teng [25]. It can also be seen that FE results at mid-plane of the adhesive layer match quite well with previous closed-form solutions.

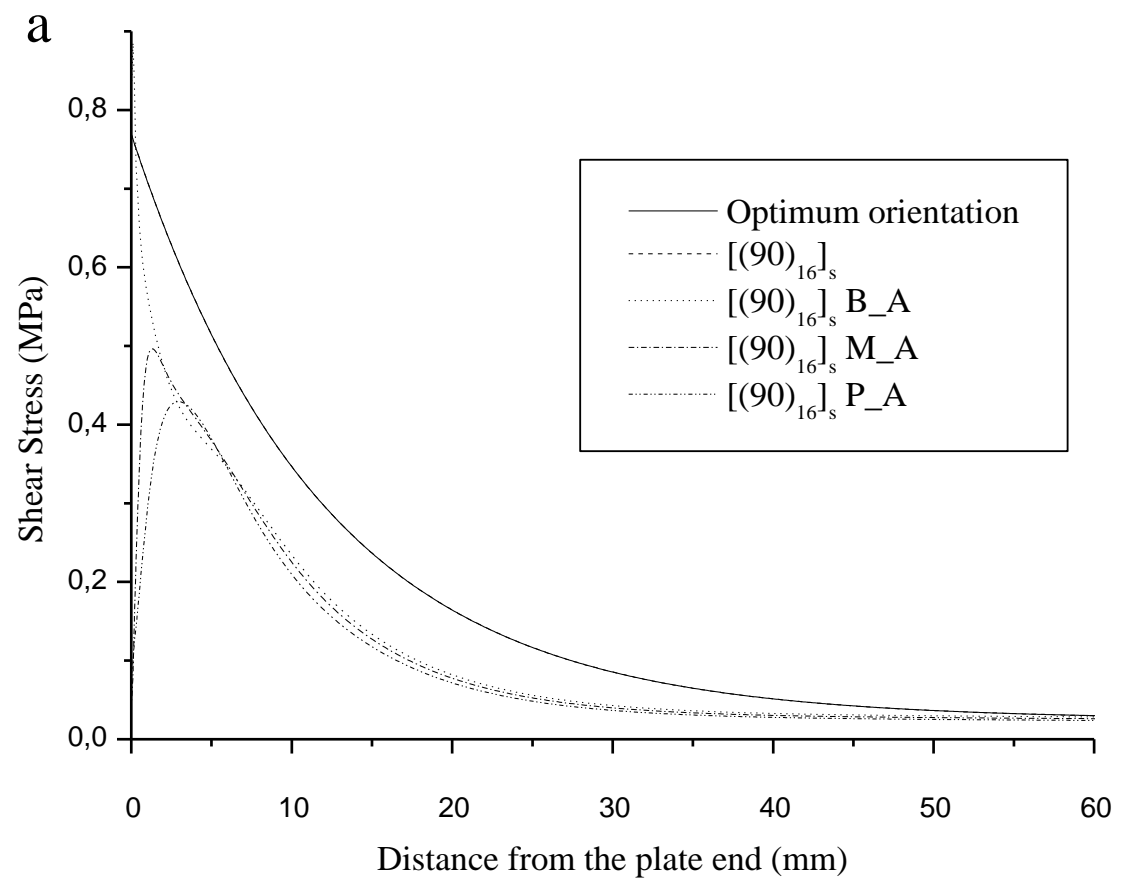




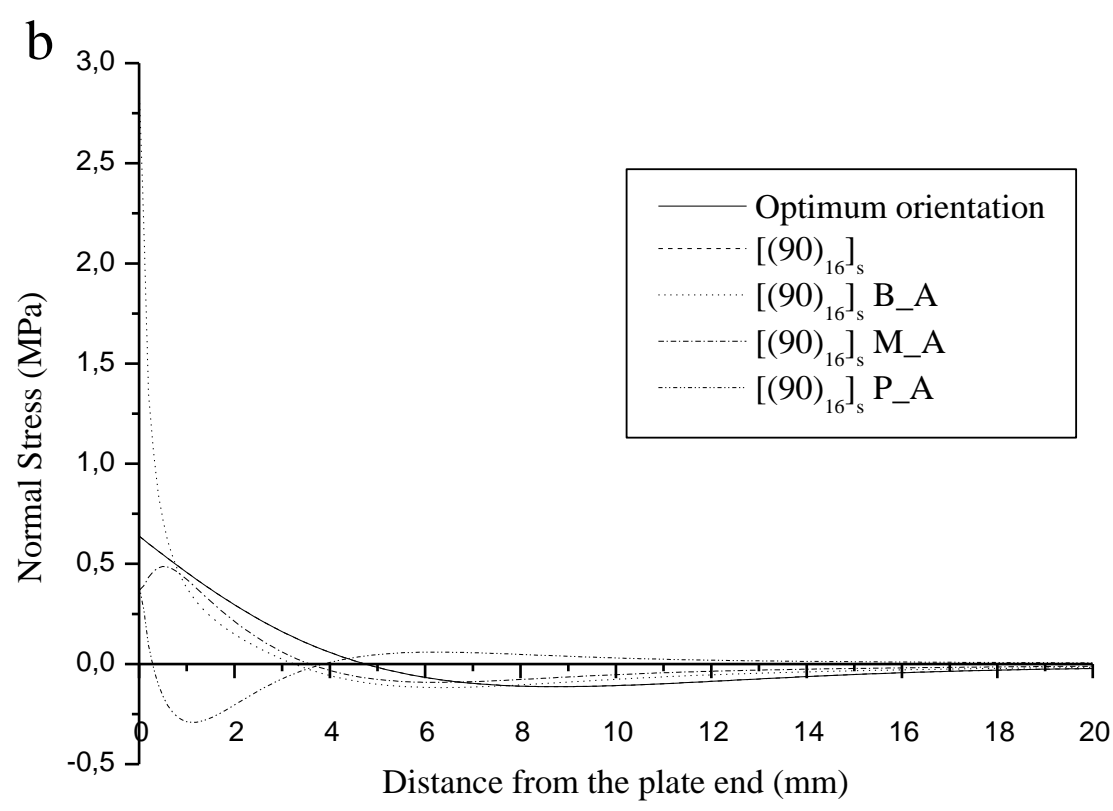

Fig.5. Comparison of shear and normal interfacial stresses in a CFRP-strengthened Concrete beam under a uniformly distributed load: theoretical models and Finite Element model (M_A: mid-plane of the adhesive layer, B_A:...)

A fibers orientation comparison using the Finite Element model has been studied. Fig. 6 and 7 show the shear and normal interfacial stresses distributions in the concrete beam bonded with a CFRP plate for each fibers orientation and for interface. This study confirms that the fibers orientation $\left[(90)_{16}\right]_{s}$ gives the minimum interfacial stresses. Configurations $\left[(0)_{8}\right]_{\mathrm{s}}, \quad\left[(90)_{8} /(60)_{8}\right]_{\mathrm{s}}, \quad\left[(90)_{8} /(45)_{8}\right]_{\mathrm{s}}$ and $\left[(45)_{8} /(-45)_{8}\right]_{\mathrm{s}}$ leads also to a significant reduction of the interfacial stresses. 

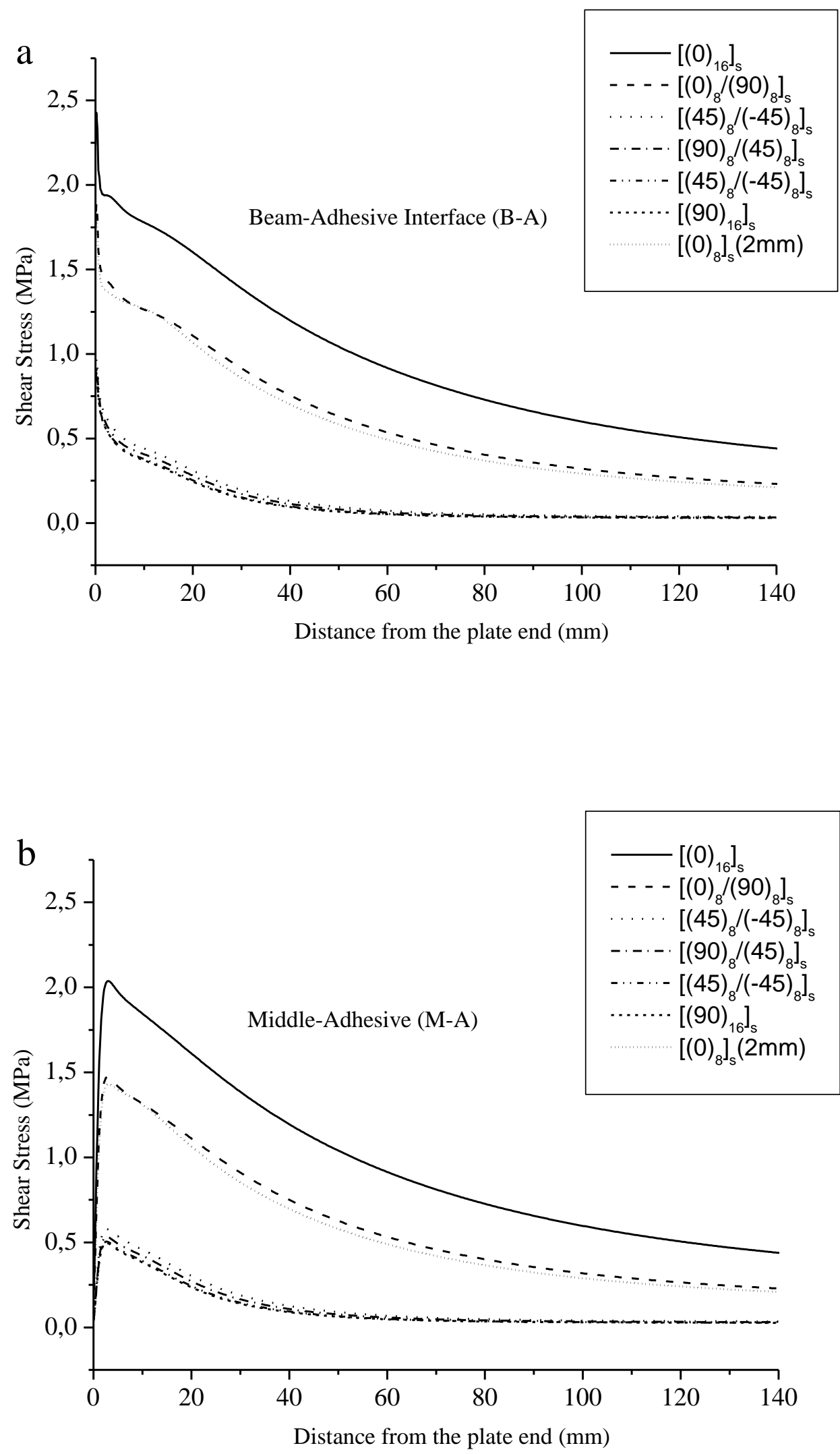


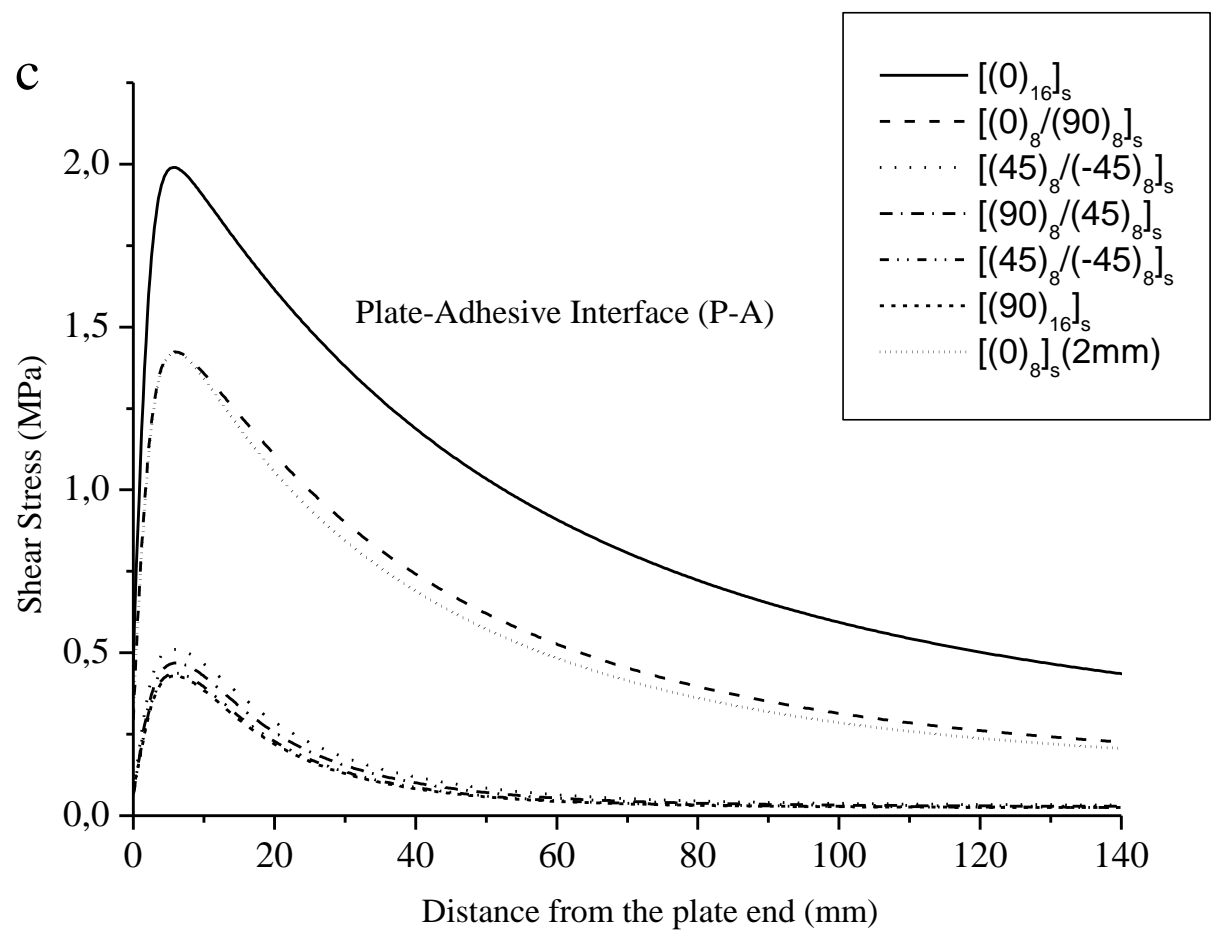

Fig.6. Interfacial shear stress in a CFRP-strengthened Concrete beam under a uniformly distributed load: finite elements model

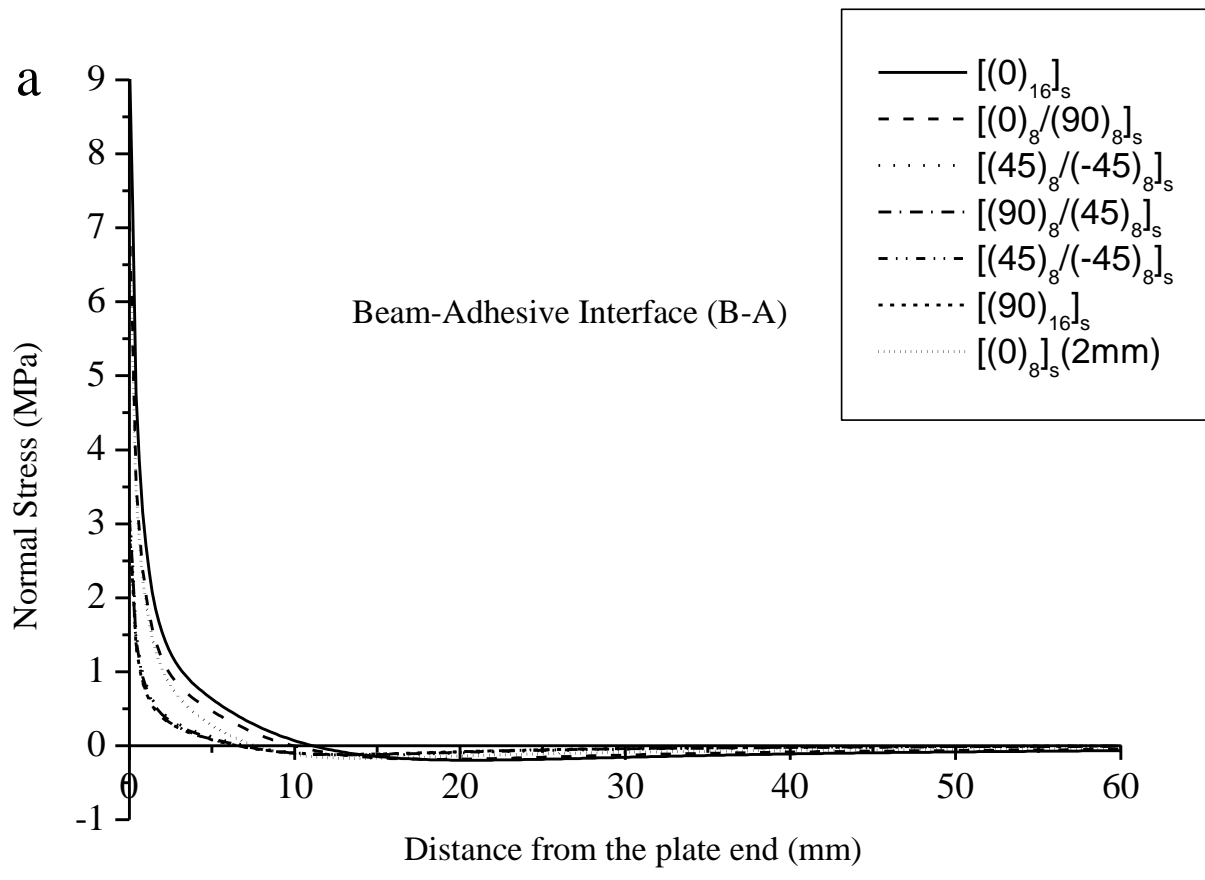



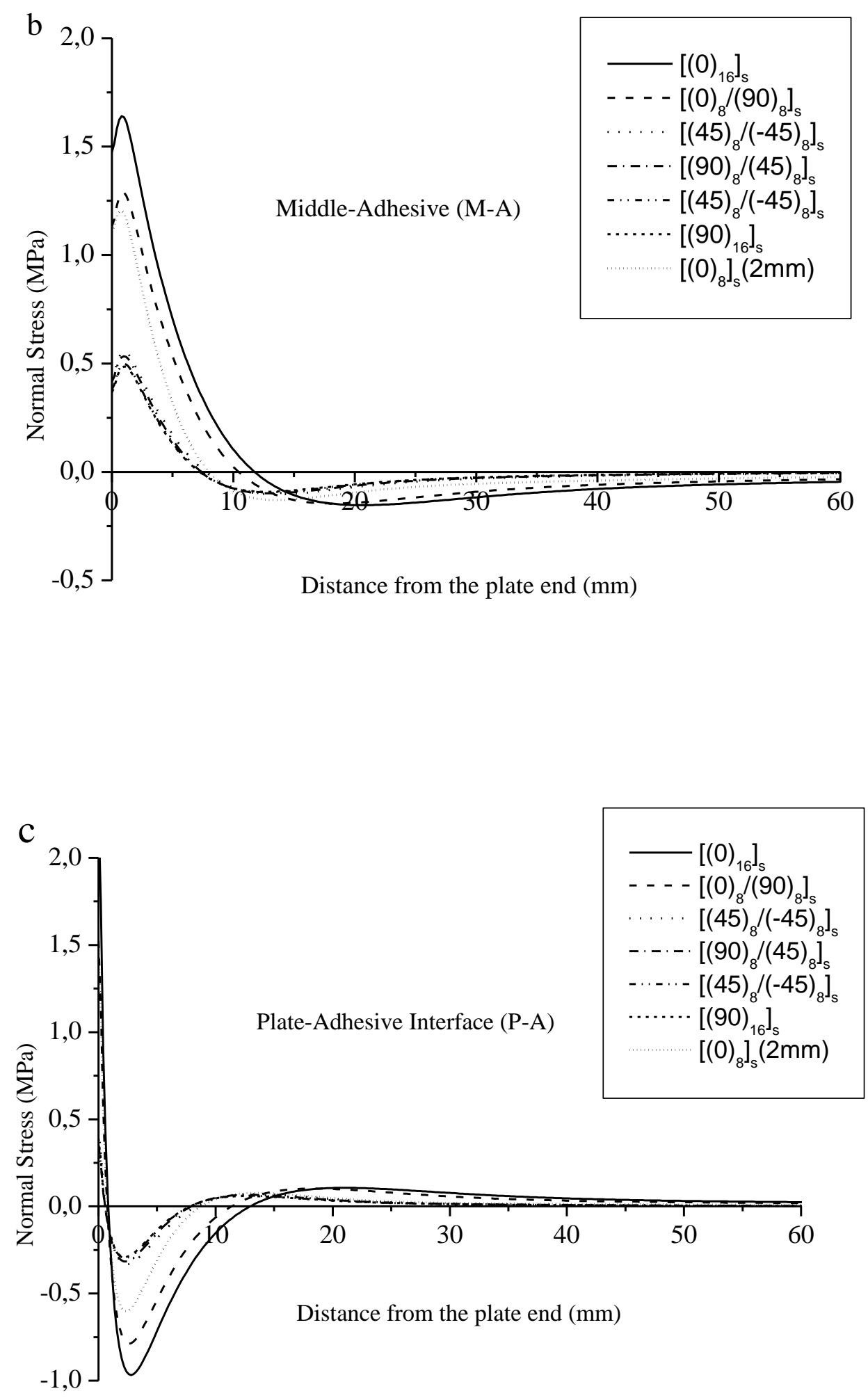

Fig.7. interfacial normal stress in a CFRP-strengthened Concrete beam under a uniformly distributed load: Finite Element model 


\subsubsection{Results for various fibers orientation: vertical displacement at mid-span}

The study described in section above shows that the minimum debonding stresses are obtained with fibers orientated perpendicularly to the longitudinal axis of the CFRP bonded plate.

However, this fibers orientation reduces the reinforcing capacity of the CFRP bonded plate due to the weak elastic modulus of the bonded plate in the perpendicular direction.

It is obvious that the maximum reinforcing capacity is reached when the fibers are oriented in the plate longitudinal direction but the debonding stresses are on their maximum as shown in the above section.

A Finite Element investigation has been established in order to find an optimum combination between debonding stresses and reinforcing capacity.

In this section, a simply supported Concrete beam without bonded CFRP plate and subjected to a uniformly distributed load is studied. This beam is used as a benchmark. Next, many cases of Concrete beam reinforced by CFRP plate with different fiber orientations combinations are modeled. The other assumptions of this numerical study are those used in the previous sections.

First, the beam displacement at the mid span and the plate end with different fibers orientation combinations is studied. This gives more information about reinforcing quality as shown in table 6

Table 6: displacements

\begin{tabular}{|l|c|c|}
\hline \multirow{2}{*}{\multicolumn{1}{|c|}{ Fiber orientation }} & \multicolumn{2}{|c|}{ UDL (50kN/m) } \\
\cline { 2 - 3 } & \multicolumn{2}{|c|}{ Displacement $(\mathrm{mm})$} \\
\cline { 2 - 3 } & Plate end & Mid span \\
\hline benchmark beam & 1.4909 & 4.2186 \\
\hline$\left[(0)_{16}\right]_{\mathrm{s}}$ & 1.3070 & 3.600 \\
\hline$\left[(0)_{8}\right]_{\mathrm{s}}(2 \mathrm{~mm}$ thickness $)$ & 1.3901 & 3.8703 \\
\hline$\left[(90)_{8} /(45)_{8}\right]_{\mathrm{s}}$ & 1.4690 & 4.1453 \\
\hline$\left[(45)_{8} /(-45)_{8}\right]_{\mathrm{s}}$ & 1.4665 & 4.1367 \\
\hline$\left[(90)_{8} /(60)_{8}\right]_{\mathrm{s}}$ & 1.4710 & 4.1518 \\
\hline$\left[(90)_{8} /(0)_{8}\right]_{\mathrm{s}}$ & 1.3798 & 3.8457 \\
\hline$\left[(90)_{16}\right]_{\mathrm{s}}$ & 1.4715 & 4.1537 \\
\hline
\end{tabular}

In table 7, the results presented in table 6 are expressed in percentages (comparison with the mid-span displacement without reinforcement); this is a way to quantify the reinforcement quality. 
Table 7: profit percentages

\begin{tabular}{|l|c|}
\hline \multirow{2}{*}{\multicolumn{1}{|c|}{ Fiber orientation }} & UDL $(50 \mathrm{kN} / \mathrm{m})$ \\
\cline { 2 - 2 } & Mean Percentages $(\%)$ \\
\hline$\left[(0)_{16}\right]_{\mathrm{s}}$ & $\mathbf{1 3 , 5 0 \%}$ \\
\hline$\left[(0)_{8}\right]_{\mathrm{s}}(2 \mathrm{~mm}$ thickness $)$ & $\mathbf{7 . 5 \%}$ \\
\hline$\left[(90)_{8} /(45)_{8}\right]_{\mathrm{s}}$ & $1,61 \%$ \\
\hline$\left[(45)_{8} /(-45)_{8}\right]_{\mathrm{s}}$ & $1,79 \%$ \\
\hline$\left[(90)_{8} /(60)_{8}\right]_{\mathrm{s}}$ & $1,46 \%$ \\
\hline$\left[(90)_{8} /(0)_{8}\right]_{\mathrm{s}}$ & $\mathbf{8 , 1 5 \%}$ \\
\hline$\left[(90)_{16}\right]_{\mathrm{s}}$ & $\mathbf{1 , 4 2 \%}$ \\
\hline
\end{tabular}

\subsection{Bearing capacity of the various reinforced Concrete beams}

In this section, the previous benchmark is another time considered except that, this time, a displacement is imposed at the mid-span of the concrete beam. The applied force is thus calculated as an outcome of the calculation. The displacement value is chosen as the ultimate stage that can be reached. This methodology allows to still use a Newton-Raphson procedure.In this part, a steel rebar is not considered too since it can besides hide the effects of the strengthening by the composite plate.

The continuum, plasticity-based damage model proposed by Lubliner et al. [39] and extended by Lee and Fenves [42] is used to represent the mechanical behavior of concrete. In the international literature, this model is also known as the "Barcelona model".

This model can take into account the plasticization (hardening and softening) of the material but also the stiffness degradation following the development of damage. The softening may eventually lead to a complete loss of strength. Specific damage coefficients in compression and in tension can be introduced. This constitutive model is thus written in the effective stresses space. Moreover, The Lubliner's model has also the advantage to use a formulation intended to alleviate strain localization effects and then mesh dependency of the results [40]. Especially a characteristic length is introduced. It is based on the element geometry: for solid elements, it is equal to the cube root of the integration point volume. This characteristic length allows to pass from the strain to the relative displacement.

Some parameters must be specified such as the yield criterion, the flow rule and the plastic behavior before and after failure begins (hardening and softening).

The yield criterion used in the Barcelona Model is the one developed by Lubliner et al. [39] and modified by Lee and Fenves [42]:

$$
F=\frac{1}{1-\alpha}\left(\bar{q}-3 \alpha \bar{p}+\beta\left(\varepsilon^{p l}\right)\left(\tilde{\bar{\sigma}}_{\max }\right\rangle-\gamma\left(\tilde{\bar{\sigma}}_{\max }\right\rangle\right)-\bar{\sigma}_{c}\left(\tilde{\varepsilon}_{c}^{p l}\right)=0
$$


With $\tilde{\bar{\sigma}}_{\text {max }}$, the maximum principal effective stress. The stresses are considered negative in compression.

In this expression, the Macaulay bracket defined as $\langle\mathrm{x}\rangle=\frac{1}{2}(|x|+x)$ is used. $\bar{p}$ is the hydrostatic effective pressure stress and $\bar{q}$ is the Mises equivalent effective stress.

$\alpha, \beta$ and $\gamma$ are material properties :

$$
\begin{aligned}
& \alpha=\frac{\left(\sigma_{b 0}-\sigma_{c 0}\right)-1}{2\left(\sigma_{b 0}-\sigma_{c 0}\right)-1} \\
& \beta=\frac{\bar{\sigma}_{c}\left(\tilde{\varepsilon}_{c}^{p l}\right)}{\bar{\sigma}_{t}\left(\tilde{\varepsilon}_{c}^{p l}\right)}(1+\alpha)-(1+\alpha) \\
& \gamma=\frac{3\left(1-K_{c}\right)}{2 K_{c}-1}
\end{aligned}
$$

According to experiments, $K_{C}$ seems to remain constant and without any other information, can be taken as equal to $2 / 3$, which gives a value of $\gamma$ equal to $3 . \sigma_{c 0}$ and $\sigma_{b 0}$ are respectively the uniaxial and the biaxial compressive strength. The common value of $\sigma_{c 0} / \sigma_{b 0}=1.16$, proposed by default in Abaqus is retained in this work.

A non-associated potential flow rule is used in the Concrete Damage Plasticity model. It is based on the Drucker-Prager hyperbolic function:

$$
G=\sqrt{\left(\in \sigma_{t 0} \tan \Psi\right)^{2}+\bar{q}^{2}}-\bar{p} \tan \Psi
$$

Where $\psi$ is the dilation angle measured in the p-q plane at high confining pressure, $\varepsilon$ is the eccentricity characterizing how close to the linear Drucker-Prager flow potential the hyperbolic function is, $\sigma_{t 0}$ is the uniaxial tensile strength.

Common values of $\varepsilon=0.1$ and $\psi=35^{\circ}$ are considered in this study.

To complete the definition of the constitutive model used to represent the concrete mechanical behavior, the user should provide the evolution of the compressive stress according to the inelastic strain (total strain minus elastic strain). These outcomes are here taken directly from the compressive 1D stress-strain curve given by the CEB-FIP [40] model (Fig.8).

Furthermore, in this model, the tensile behaviour is represented with a smeared crack approach (of Hillerborg type [41]). In order to alleviate strain localization, the evolution of the post-peak stress has to be implemented as a tabular function of the displacement across the crack (crack opening distance). The CEB-FIP [40] model is another time considered (Fig. 9). 


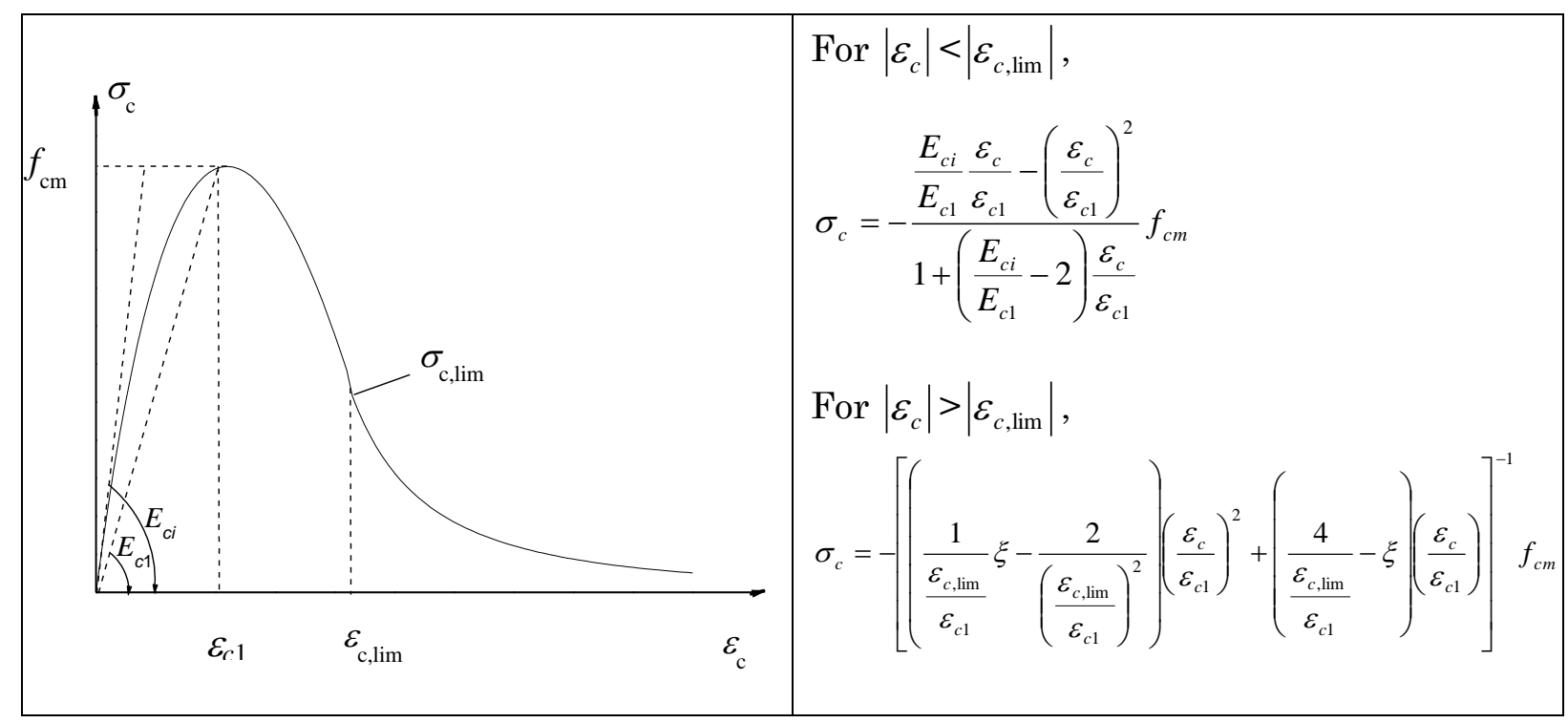

Fig.8. Stress-strain diagram for uniaxial compression (CEB-FIP)

\begin{tabular}{|c|c|}
\hline $\begin{array}{l}\frac{E_{c i}}{0.00015} \\
\text { For } \sigma_{c t} \leq 0.9 f_{c t m}, \\
\sigma_{c t}=E_{c i} \varepsilon_{c t} \\
\text { For } 0.9 f_{c t m}<\sigma_{c t} \leq f_{c t m}, \\
\sigma_{c t}=f_{c t m}-\frac{0.1 f_{c t m}}{0.00015-0.9 \frac{f_{c t m}}{E_{c i}}}\left(0.00015-\varepsilon_{c t}\right)\end{array}$ & $\begin{array}{l}\text { For } 0.15 f_{c t m} \leq \sigma_{c t} \leq f_{c t m}, \\
\sigma_{c t}=f_{c t m}\left(1-\frac{w}{w_{c t m}}\right) \\
\text { For } 0 \leq \sigma_{c t} \leq 0.15 f_{c t m}, \\
\sigma_{c t}=\frac{0.15 f_{c t m}}{w_{c}-w_{1}}\left(w_{c}-w\right) \\
w_{F}=G_{F 0}\left(\frac{f_{c m}}{f_{c m 0}}\right)^{0.7} \\
w_{F}\end{array}$ \\
\hline
\end{tabular}

Fig.9. Stress-strain stress-crack opening diagram for uniaxial tension (CEB-FIP). 
In the present study, we have taken: $f_{\mathrm{cm}}=25 \mathrm{Mpa}, \varepsilon_{\mathrm{c}, \mathrm{lim}}=0,0042, E_{\mathrm{c} 1}=11,36 \mathrm{GPa} ; f_{\mathrm{ctm}}=1.99 \mathrm{MPa}$; $w_{1}=0,027 \mathrm{~mm} ; w_{c}=0,2 \mathrm{~mm} ; E_{c i}=29,18 \mathrm{GPa} ; G_{F 0}=0.03 \mathrm{Nmm} / \mathrm{mm}^{2} ; G_{F}=0.057 \mathrm{Nmm} / \mathrm{mm}^{2} ; \alpha_{F}=7$ for a maximum aggregate size equal to $16 \mathrm{~mm}$ )

Where $w_{1}$ and $w_{c}$ are respectively the crack openings for $\sigma_{c k}=0.15 f_{c t m}$ and $\sigma_{c t}=0, f_{c t m}$ is the tensile strength, $G_{F}$ is the fracture energy and $\alpha_{F}$ is the coefficient given bay Table 2.18 within CEBFIP [40]. The fracture energy $G_{F}$ is calculated using the formula (2.1-7) in the CEB-FIP [40] where $f_{c m 0}$ is taken equal to $10 \mathrm{MPa}$ and $G_{F 0}$ is the base value of fracture energy and it depends on the maximum aggregate size.

\subsubsection{Discussion about the best reinforcement}

Fig. 10 plots the applied force with imposed displacement for the benchmark beam and for each fiber orientation combination. Three main families of results are put into evidence. Combinations presenting fibers along the longitudinal axis $\left(\left[(0)_{16}\right]_{\mathrm{s}} \quad\left[(90)_{8} /(0)_{8}\right]_{\mathrm{s}} \quad\left[(45)_{8} /(0)_{8}\right]_{\mathrm{s}}\right)$ provide the best reinforcement whereas combinations with fibers perpendicular to $\mathrm{x}$-axis $\left(\left[(90)_{16}\right]_{\mathrm{s}},\left[(90)_{8} /(45)_{8}\right]_{\mathrm{s}},\left[(90)_{8} /(60)_{8}\right]_{\mathrm{s}}\right)$ lead to an intermediate result. Finally, the reference beam plot gives the ultimate force supported by the Concrete beam without the soffit plate. The combination $\left[(90)_{8} /(0)_{8}\right]_{\mathrm{s}}$ leads to two advantages, the first one is an ultimate force near to the high delimiter $\left[(0)_{16}\right]_{\mathrm{s}}$ and the second is a weak debonding stresses compared with the combination $\left[(0)_{16}\right]_{s}$.

It is also important to note that adding a $2 \mathrm{~mm}$ fiber layer $\left[(90)_{8}\right]_{\mathrm{s}}$ to the $\left[(0)_{8}\right]_{\mathrm{s}}$ composite, leading to a $\left[(90)_{8} /(0)_{8}\right]_{\mathrm{s}}$ composite of $4 \mathrm{~mm}$ thickness, improves the strengthening quality without increasing the debonding stresses as shown in Table 4 and Fig.10. However, the $\left[(0)_{16}\right]_{\mathrm{s}}$ composite improves the bearing capacity but increases in the same time the debonding risk. 


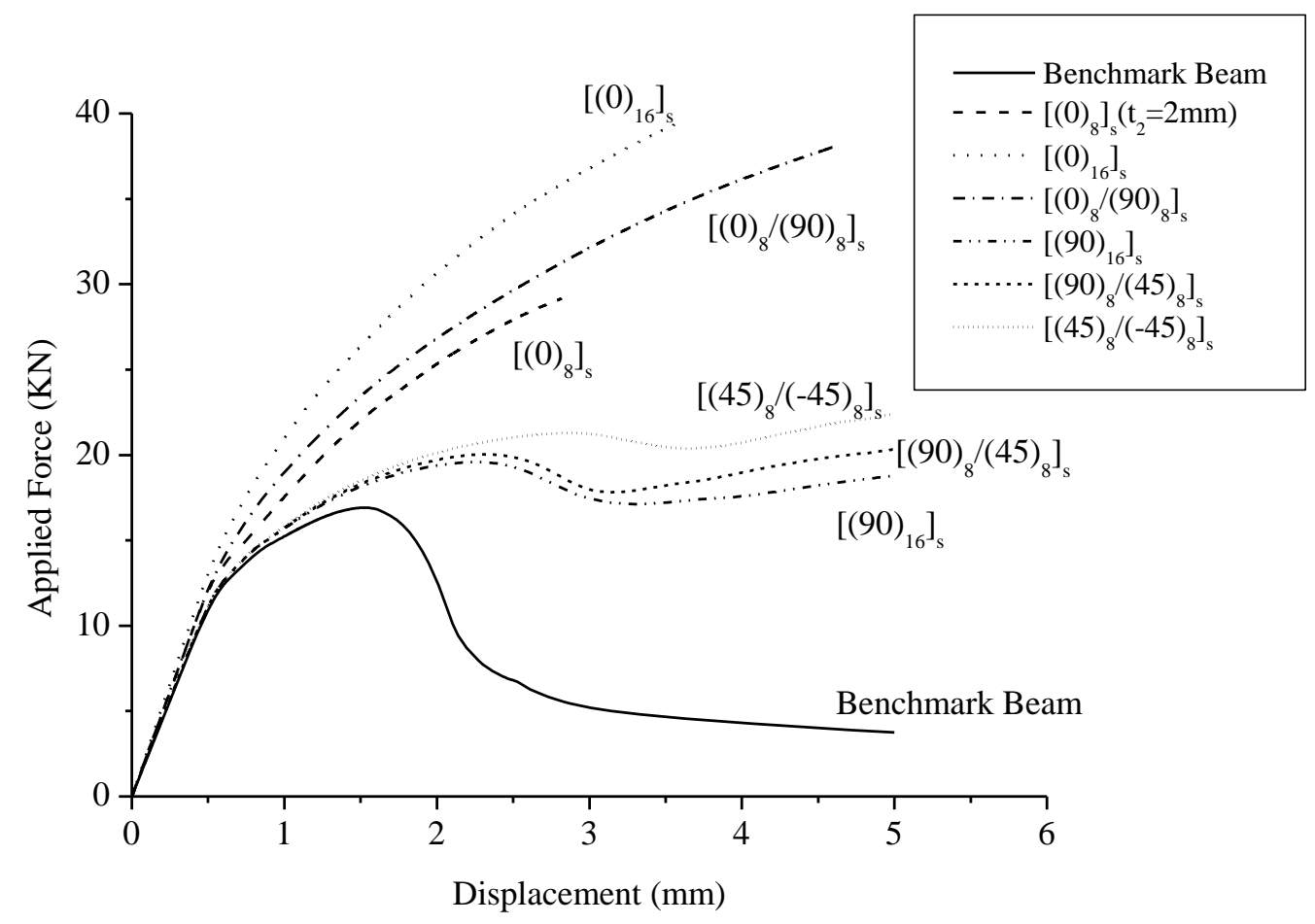

Fig.10. Force-displacement plot for different fibers orientations

\section{Conclusion:}

A new theoretical interfacial stress analysis has been presented for simply supported beams bonded with a FRP plate. The solution presented in this paper is based on the minimization of the interfacial stresses by varying fiber orientations.

The fiber orientation giving the minimum of debonding stresses is not a good solution for the strengthening quality as shown by the finite elements investigation. However, it has been shown that the fiber orientation combination $\left[(90)_{\mathrm{n}} /(0)_{\mathrm{n}}\right]_{\mathrm{s}}$ is a good solution reconciling debonding stresses and strengthening quality.

A steel reinforcement has not been considered explicitly in this study but the results can be transferred to the case of the reinforced concrete. The steel rebar has no influence on the elastic behavior of the whole beam. Concerning the non-elastic behavior, the rebar may partially hide the effect of the composite plate but it will not modify the ranking of Figure 10, and the contributions of each studied composite plate. 


\section{References:}

[1] An W, Saadatmanesh H, Ehsani MR. RC beams strengthened with FRP plates: II. Analysis and parametric study. J Struct Eng ASCE 1991; 117(11):3434-55.

[2] Saadatmanesh H, Ehsani MR. RC beams strengthened with GFRP plates: I. Experimental study. J Struct Eng ASCE 1991; 117(11):3417-33.

[3] Sharif A, Al-Sulaimani GJ, Basunbul IA, Baluch MH, Ghaleb BN. Strengthening of initially loaded reinforced concrete beams using FRP plates. ACI Struct J 1994; 91(2):160-8.

[4]Chajes MJ, Thomson Jr. TA, Januszka TF, Finch Jr. WW. Flexural strengthening of concrete beams using externally bonded composite materials. Construct Build Mater 1994; 8(3):191-201.

[5]Quantrill RJ, Hollaway LC, Thorne AM. Experimental and analytical investigations of FRPstrengthened beam response: part I. Mag Concrete Res 1996; 48(177):331-42.

[6] Quantrill RJ, Hollaway LC, Thorne AM. Predictions of the maximum plate end stresses of FRP strengthened beams: part II. Mag Concrete Res 1996; 48(177):343-51.

[7] Arduini M, Nanni A. Parametric study of beams with externally bonded FRP reinforcement. ACI Struct J 1997; 94(5):493-501.

[8] Wu Z, Matsuzaki T, Tanabe K. Interface crack propagation in FRPstrengthened concrete structures. Non-metallic (FRP) reinforcement for concrete structures, vol. 1. Japan: Japan Concrete Institute; 1997.p. 319-26.

[9]Lau KT, Dutta PK, Zhou LM, Hui D. Mechanics of bonds in a FRP bonded concrete beam. J Compos Part B 2001; 32:491-502.

[10] Saadatmanesh H, Malek AM. Design guidelines for flexural strengthening of RC beams with FRP plates. J Compos Construct ASCE 1998; 2(4):158-64.

[11] Spadea G, Bencardino F, Swamy RN. Structural behavior of composite RC beams with externally bonded CFRP. J Compos Construct ASCE 1998; 2(3):132-7.

[12] Raoof M, El-Rimawi JA, Hassanen AH. Theoretical and experimental study on externally plated R.C. beams. Eng Struct 2000; 22:85-101.

[13] Triantafillou TC, Antonopoulos CP. Design of concrete flexural members strengthened in shear with FRP. J Compos Construct ASCE 2000; 4(4):198-205.

[14] Foraboschi P. Analytical solution of two-layer beam taking into account non-linear interlayer slip. ASCE J. Eng. Mech. 2009; 135(10): 1129-1146.

[15] Foraboschi P. Behavior and Failure Strength of Laminated Glass Beams. ASCE J. Eng. Mech. 2007; 133(12): 1290-1301.

[16] O. Vilnay. The analysis of reinforced concrete beams strengthened by epoxy bonded steel plates, Int. J. Cement Compos. Lightweight Concrete 10, 73-78 (1988).

[17] T. M. Roberts. Approximate analysis of shear and normal stress concentrations in the adhesive layer of plated RC beams. Struct. Engr. 67, 229-233 (1989). 
[18] T. M. Roberts and H. Haji-Kazemi. Theoretical study of the behavior of reinforced concrete beams strengthened by externally bonded steel plates. Proc. Inst. Civil Engrs 87, 39-55 (1989).

[19] B. Taljsten, Strengthening of beams by plate bonding, J. Mater. Civil Eng. ASCE 9, 206-212 (1997).

[20] A. M. Malek, H. Saadatmanesh and M. R. Ehsani, Prediction of failure load of R/C beams strengthened with FRP plate due to stress concentration at the plate end. ACI Struct. J. 95, 142152 (1998).

[21] S. T. Smith and J. G. Teng, Interfacial stresses in plated beams. Eng. Struct. 23, 857-871 (2001).

[22] A. Tounsi. Improved theoretical solution for interfacial stresses in concrete beams strengthened with FRP plate. Int. J. Solids Struct. 43, 4154-4174 (2006).

[23] A. Tounsi and S. Benyoucef. Interfacial stresses in externally FRP plated concrete beams. Int. J. Adhes. Adhes. 27, 207-215 (2007).

[24] C. S. Cai, J. Nie and X. M. Shi. Interface slip effect on bonded plate repairs of concrete beams. Eng. Struct. 29, 1084-1095 (2007).

[25] A. Tounsi, T. Hassaine Daouadji, S. Benyoucef and E. A. Adda Bedia. Interfacial stresses in FRP-plated RC beams: effect of adherend shear deformations. Int. J. Adhes. Adhes. 29, 343-351 (2009).

[26] Smith ST, Teng JG. FRP-strengthened RC beams-I: Review of debonding strength models. Eng Struct 2002;24(4):385_95.

[27] L. Zhang, J.G. Teng .Finite element prediction of interfacial stresses in structural members bonded with a thin plate. Engineering Structures 32 (2010) $459-471$.

[28] Chen JF, Teng JG. Anchorage strength models for FRP and steel plates bonded to concrete. J Struct Eng ASCE 2001;127(1):784-91.

[29] Bakis CE, Bank LC, Brown VL, Cosenza E, Davalos JF, Lesko JJ. Fiber-reinforced polymer composites for construction state-of-the-art review. J Compos Construct ASCE 2002;6(2):73-87.

[30] Smith ST, Teng JG. FRP-strengthened RC beams. II: assessment of debonding strength models. Eng Struct 2002;24(4):397-417.

[31] Chen JF, Teng JG. Shear capacity of FRP-strengthened RC beams: FRP debonding. Construct Build Mater 2003;17:27-41.

[32] Yuan H, Teng JG, Seracino R, Wu ZS, Yao J. Full-range behavior of FRP-to-concrete bonded joints. Eng Struct 2004;26:553-65.

[33] Gao B, Leung CKY, Kim JK. Prediction of concrete cover separation failure for RC beams strengthened with CFRP strips. Eng Struct 2005;27:177-89.

[34] Shen HS, Teng JG, Yang J. Interfacial stresses in beams and slabs bonded with a thin plate. J Eng Mech ASCE 2001;127(4):399-406.

[35] Stratford T, Cadei J. Elastic analysis of adhesion stresses for the design of a strengthened plate bonded to a beam. Construct Build Mater 2006;20:34-5. 
[36] Herakovich CT. Mechanics of fibrous composites. USA: Wiley; 1998.

[37] Nelder. J. A., Mead. R. "A simplex method for function minimization", The Computer Journal (1695) 7 (4): 308-313.

[38] ABAQUS. Version 6.9 user's manual. USA: Hibbit, Karlsson \& Sorensen; 2009.

[39] Lubliner J., Oliver J., Oller S., Oñate E. A plastic-damage model for concrete. International Journal of Solids and Structures, Vol. 25, No. n 3, 1989, , pp. 299--326.

[40] CEB-FIP Model code 1990, Design code. Thomas Telford services, 1998.

[41] Hillerborg A., Modeer M., Petersson P.E. Analysis of Crack Formation and Crack Growth in Concrete by Means of Fracture Mechanics and Finite Elements. Cement and Concrete Research, Vol. 6, No. $n^{\circ} 6,1976$, pp. 773--782.

[42] Lee and Fenves, . "Plastic-Damage Model for Cyclic Loading of Concrete Structures". J. Eng. Mech., 124(8) 1998., 892-900. 